\title{
SP600125 reduces lipopolysaccharide-induced apoptosis and restores the early-stage differentiation of osteoblasts inhibited by LPS through the MAPK pathway in MC3T3-E1 cells
}

\author{
CHUN GUO $^{1 *}$, SHENG-LI WANG $^{2 *}$, SONG-TAO XU ${ }^{1 *}$, JIAN-GUO WANG $^{1}$ and GUO-HUA SONG ${ }^{1}$ \\ ${ }^{1}$ Department of Medicine, Luohe Medical College, Luohe, Henan 462002; \\ ${ }^{2}$ First Affiliated Hospital, Henan University, Kaifeng, Henan 475000, P.R. China
}

Received July 16, 2014; Accepted March 4, 2015

DOI: $10.3892 /$ ijmm.2015.2130

\begin{abstract}
Bone degradation is a serious complication of chronic inflammatory diseases such as septic arthritis, osteomyelitis, and infected orthopedic implant failure. Effective therapeutic treatments for bacteria-caused bone destruction are limited. In a previous study, we found that lipopolysaccharide (LPS) induced osteoblast apoptosis and inhibited early and late-stage differentiation of osteoblasts via activation of the C-Jun N-terminal kinase (JNK) pathway. This study aimed to investigate the effect of JNK inhibition by SP600125 on the apoptosis and differentiation of MC3T3-E1 osteoblasts suppressed by LPS. Following pretreatment with SP600125 for $2 \mathrm{~h}, \mathrm{MC} 3 \mathrm{~T} 3-\mathrm{E} 1$ cells were treated LPS. Following this treatment, cell viability, activity of alkaline phosphatase (ALP) and caspase-3 were measured. mRNA and protein expression of osteoblast-specific genes, mitogen-activated protein kinases (MAPKs), Bax, Bcl-2 and caspase-3 were determined by quantitative polymerase chain reaction (qPCR) and western blot analysis. The results showed that SP600125 significantly restored LPS-inhibited cell metabolism and ALP activity and reduced the upregulated caspase-3 activity of MC3T3-E1 cells induced by LPS. SP600125 also significantly restored the LPS-suppressed mRNA and protein expression levels of earlystage osteoblast-associated genes in a dose-dependent manner. SP600125 significantly downregulated expression of Bax and caspase-3 but upregulated Bcl-2 expression in MC3T3-E1 cells stimulated by LPS. Furthermore, SP600125 selectively triggered the MAPK pathway by reducing the expression of JNK1,
\end{abstract}

Correspondence to: Dr Jian-Guo Wang or Professor Guo-Hua Song, Luohe Medical College, 148 Daxue Road, Luohe, Henan 462002, P.R. China

E-mail: yebotao12@126.com

E-mail: lhyzsgh@163.com

*Contributed equally

Key words: osteoblasts, lipopolysaccharide, SP600125, mitogenactivated protein kinases while enhancing the expression of extracellular signal-regulated kinase 1 (ERK1). Our results suggested that SP600125 reduced LPS-induced osteoblast apoptosis and restored earlystage differentiation of osteoblasts inhibited by LPS through MAPK signaling. These findings suggest that the therapeutic agent that inhibited JNK1 is of potential use for the restoration of osteoblast function in bacteria-induced bone diseases.

\section{Introduction}

Bone is a dynamic tissue that constantly undergoes remodeling in which a coupled process of bone formation by osteoblasts and resorption by osteoclasts continues throughout life (1). An imbalance between bone formation and resorption results in excessive bone loss, a feature of chronic inflammatory diseases such as rheumatoid arthritis, osteomyelitis, bacterial arthritis and infection of orthopedic implants (2).

Lipopolysaccharide (LPS), a component of the outer membranes of gram-negative bacteria, was shown to be capable of inducing bone resorption in vitro or in vivo (3-8). LPS can also inhibit osteoblast differentiation and function in cell cultures (9-12). However, effective therapy, such as treatment with antibiotics and surgery, against chronic inflammatory diseases such as bacteria-induced bone destruction is limiting. Therefore, the study and development of potential drugs that can restore osteoblast function remains a fundamental objective in the prevention of bone destruction in infective bone diseases.

C-Jun N-terminal kinases (JNKs) are protein kinases involved in cell apoptosis and the inflammatory response $(13,14)$. JNK1, JNK2 and JNK3 are genetic loci encoded in the mammalian genome, with JNK1 and JNK2 being ubiquitously expressed, while JNK3 is expressed predominantly in the brain and to a lesser extent in the heart and testis (15). However, evidence suggesting that JNK1, but not JNK2 or JNK3, is the key JNK family kinase responsible for the phosphorylation of c-Jun and for the expression of RNA polymerase III. In many cells, JNK1, but not JNK2, mediates tumor necrosis factor- $\alpha$ (TNF- $\alpha$ )-induced cell apoptosis by inhibiting cell differentiation and promoting the generation of inflammatory cytokines such as interleukin-6 (IL-6) and LIF (16-18). In a previous study, we found that LPS induced osteoblast apoptosis and inhibited osteoblast differentiation via activation of the JNK 
pathway (19). Therefore, the aim of the present study was to evaluate the effect of JNK inhibition by SP600125 on the apoptosis and osteoblast differentiation in MC3T3-E1 cells stimulated with LPS.

\section{Materials and methods}

Reagents. Escherichia coli LPS (serotype 055:B5), $\beta$-glycerophosphate ( $\beta$-GP), 4-(2-hydroxyethyl)-1-piperazineethanesulfonic acid (HEPES), and ascorbic acid were purchased from Sigma Chemical Co. (St. Louis, MO, USA). The protease inhibitor cocktail, and the selective mitogenactivated protein kinase (MAPK) inhibitors, SP600125 and PD98059 were purchased from Calbiochem (San Diego, CA, USA). Dulbecco's modified Eagle's medium (DMEM), fetal bovine serum (FBS) and penicillin/streptomycin were purchased from Gibco (Rockville, MD, USA). Antibodies to c-Jun N-terminal kinase 1 (JNK1), extracellular signal-regulated kinase 1 (ERK1), alkaline phosphatase (ALP) and caspase-3 were purchased from Cell Signaling Technology (Beverly, MA, USA). Antibodies to Runx2, osterix (OSX), osteocalcin (OCN), Bax, Bcl-2 and $\beta$-actin were purchased from Santa Cruz Biotechnology, Inc. (Santa Cruz, CA, USA). MC3T3-E1 cells, an osteoblast-like cell line was obtained from the American Type Culture Collection (ATCC, Manassas, VA, USA). Other chemicals and reagents used in this study were of analytical grade.

Cell culture. MC3T3-E1 cells were grown in DMEM supplemented with $10 \%$ (v/v) FBS, $1 \%$ (v/v) penicillin-streptomycin solution, $10 \mathrm{mM}$ HEPES solution and incubated at $37^{\circ} \mathrm{C}$ in $5 \% \mathrm{CO}_{2}$ humidified air. To examine the effect of SP600125 on osteoblast differentiation stimulated with LPS, MC3T3-E1 cells at a density of $5 \times 10^{4}$ cells $/ \mathrm{cm}^{2}$ were cultured in osteogenic differentiation medium (DMEM with $10 \%$ FBS, $10 \mathrm{mM}$ HEPES, $50 \mu \mathrm{g} / \mathrm{ml}$ L-ascorbic acid and $5 \mathrm{mM} \beta-\mathrm{GP}$ ) for 2 days. On differentiation day 3 , following pretreatment with or without SP600125 for $2 \mathrm{~h}$, the cells were treated with 100 and $1,000 \mathrm{ng} / \mathrm{ml}$ LPS or without LPS at the indicated time points.

MTT assay. Cell metabolism was measured using MTT assay. MC3T3-E1 cells at a density of $5 \times 10^{3}$ cells $/ \mathrm{cm}^{2}$ were plated in 96-well culture plates and cultured in $0.2 \mathrm{ml}$ osteogenic differentiation medium. Following pretreatment with 5, 10, 15, 25 and $50 \mu \mathrm{M}$ SP600125 or without SP600125 for $2 \mathrm{~h}$, the cells were treated with 100 and $1,000 \mathrm{ng} / \mathrm{ml}$ LPS or without LPS for 1 and 3 days. At the end of treatment, $20 \mu \mathrm{MTT}(5 \mathrm{mg} / \mathrm{ml})$ was added to each well. The cells were cultured for an additional $4 \mathrm{~h}$, the supernatant was removed, and $100 \mu \mathrm{l}$ dimethyl sulfoxide (DMSO) was added to each well. After agitation for 3 min, absorbance was measured at $490 \mathrm{~nm}$ using a microplate reader (Thermo Fisher Scientific, Inc., Pittsburgh, PA, USA). The experiment was performed in triplicate.

ALP activity determination. MC3T3-E1 cells at $5 \times 10^{5}$ cells $/ \mathrm{cm}^{2}$ were seeded in 100-mm diameter culture dishes and cultured in osteogenic differentiation medium for 2 days. On differentiation day 3 , following pretreatment with 25 and $50 \mu \mathrm{M}$ SP600125 or without SP600125 for $2 \mathrm{~h}$, the cells were treated with 100 and 1,000 $\mathrm{ng} / \mathrm{ml}$ LPS or without LPS in osteogenic differentiation medium for 1 and 2 days. The cells were detached aided by a cell scraper in phosphate-buffered saline (PBS), and then centrifuged at 16,000 x g for $5 \mathrm{~min}$. Cell pellets were placed in $300 \mu \mathrm{l}$ of lysis buffer (Cytobuster protein extraction reagent; Novagen, Darmstadt, Germany) with 1X protease inhibitor cocktail. The ALP activity in the lysates was determined by the measurement of p-nitrophenyl phosphate (pNPP) using a commercial assay kit (Beyotime Institute of Biotechnology, Shanghai, China) according to the manufacturer's instructions. Briefly, cell lysate of each sample was added to the assay buffer ( $2 \mathrm{mM} \mathrm{MgCl}_{2}, 50 \mathrm{mM}$ Tris- $\mathrm{HCl} /$ $\mathrm{pH}$ 9.8) containing $2.5 \mathrm{mM}$ pNPP. After 30-min incubation at $37^{\circ} \mathrm{C}$, the reaction was terminated by the addition of $0.2 \mathrm{M}$ $\mathrm{NaOH}$. Absorbance of the reaction mixture was measured by spectrophotometry (Eppendorf BioSpectrometer; Eppendorf AG, Hamburg, Germany) at $405 \mathrm{~nm}$. A standard curve was also generated using a series of diluted colored p-nitrophenol (pNP) with known concentrations. The concentration was calculated by projecting the optical densities on the standard curve. Total protein concentrations were quantified by spectrophotometry (Eppendorf BioSpectrometer). The relative ALP activity was defined as micromoles of pNPP hydrolyzed per minute per $1 \mathrm{~g}$ of total protein (18).

Measurement of caspase-3 activity. MC3T3-E1 cells at a density of $5 \times 10^{5}$ cells $/ \mathrm{cm}^{2}$ were seeded in $100-\mathrm{mm}$ diameter culture dishes and cultured in osteogenic differentiation medium for 2 days. On differentiation day 3 , following pretreatment with 25 and $50 \mu \mathrm{M}$ SP600125 or without SP600125 for $2 \mathrm{~h}$, the cells were treated with 100 and 1,000 $\mathrm{ng} / \mathrm{ml}$ LPS or without LPS in osteogenic differentiation medium for 1 and 2 days. The activity of caspase- 3 was determined using the caspase-3 activity kit (Beyotime Institute of Biotechnology) according to the manufacturer's instructions. Briefly, the cells were detached aided by a cell scraper in PBS buffer, then centrifuged at $16,000 \mathrm{x}$ g for $5 \mathrm{~min}$ and the cell pellets were placed in $300 \mu \mathrm{l}$ of lysis buffer (cytobuster protein extraction reagent) with $1 \mathrm{X}$ protease inhibitor cocktail. Total protein concentrations were quantified by spectrophotometry (Eppendorf BioSpectrometer). The cell lysates of each sample were then incubated with a mixture provided in the kit, containing caspase-3 assay buffer, Ac-DEVD-pNA, the substrate of caspase-3. After 2 -h incubation at $37^{\circ} \mathrm{C}$, the optical density (coloration) resulting from the cleavage of the substrate and the release of pNA, was detected and quantified by spectrophotometry (Eppendorf BioSpectrometer) at $405 \mathrm{~nm}$. A standard curve was also generated using a series of diluted pNA with known concentrations. The concentration was calculated by projecting the optical densities on the standard curve. The relative caspase- 3 activity was defined as nanomoles of pNA per minute per $1 \mathrm{mg}$ of total protein. All the experiments were carried out in triplicate.

Quantitative PCR. Total RNA was isolated using TRIzol reagent (Invitrogen, Grand Island, NY, USA) and quantified by spectrophotometry. After isolation, $3 \mu \mathrm{g}$ total RNA from each sample was reverse transcribed (RT) utilizing the HiFi-MMLV cDNA kit (Beijing CoWin Biotech, Beijing, China) according to the manufacturer's instructions. The primer sequences of osteoblast-associated genes, caspase-3, Bax, Bcl-2, JNK1 and ERK1 
Table I. Primer sequences used for quantitative PCR.

\begin{tabular}{|c|c|c|c|c|}
\hline Gene & $\begin{array}{l}\text { Primer sequences } \\
\qquad\left(5^{\prime} \rightarrow 3^{\prime}\right)\end{array}$ & $\begin{array}{c}\text { Accession } \\
\text { no. }\end{array}$ & $\begin{array}{c}\text { Annealing } \\
\text { temperature }\left({ }^{\circ} \mathrm{C}\right)\end{array}$ & $\begin{array}{l}\text { Product size } \\
\text { (bp) }\end{array}$ \\
\hline \multirow[t]{2}{*}{ Runx2 } & F: TTCAACGATCTGAGATTTGTGGG & & & \\
\hline & R: GGATGAGGAATGCGCCCTA & NM_001146038 & 62 & 221 \\
\hline \multirow[t]{2}{*}{$A L P$} & F: GAGCGTCATCCCAGTGGAG & & & \\
\hline & R: TAGCGGTTACTGTAGACACCC & NM_007433 & 62 & 158 \\
\hline \multirow[t]{2}{*}{$B S P$} & F: CAGGGAGGCAGTGACTCTTC & & & \\
\hline & R: AGTGTGGAAAGTGTGGCGTT & NM_008318 & 58 & 158 \\
\hline \multirow[t]{2}{*}{$O S X$} & F: ATGGCGTCCTCTCTGCTTG & & & \\
\hline & R: TGAAAGGTCAGCGTATGGCTT & NM_130458 & 62 & 156 \\
\hline \multirow[t]{2}{*}{$O C N$} & F: GAGGGCAATAAGGTAGTGAA & & & \\
\hline & R: CATAGATGCGTTTGTAGGC & NM_001037939 & 62 & 160 \\
\hline \multirow[t]{2}{*}{ Collal } & F: CCCTGCCTGCTTCGTGTA & & & \\
\hline & R: TTGAGTTTGGGTTGTTCGTC & ВC003198 & 63 & 101 \\
\hline \multirow[t]{2}{*}{ Caspase-3 } & F: TGGTGATGAAGGGGTCATTTATG & & & \\
\hline & R: TTCGGCTTTCCAGTCAGACTC & ВC038825 & 60 & 105 \\
\hline \multirow[t]{2}{*}{ Bax } & F: AGACAGGGGCCTTTTTGCTAC & & & \\
\hline & R: AATTCGCCGGAGACACTCG & NM_007527 & 60 & 137 \\
\hline \multirow[t]{2}{*}{$B c l-2$} & F: GTCGCTACCGTCGTGACTTC & & & \\
\hline & R: GACCCCACCGAACTCAAAGAA & NM_177410 & 66 & 152 \\
\hline \multirow[t]{2}{*}{$\beta$-actin } & F: GGCTGTATTCCCCTCCATCG & & & \\
\hline & R: CCAGTTGGTAACAATGCCATGT & NM_007393 & 60 & 154 \\
\hline
\end{tabular}

F, forward; R, reverse; PCR, polymerase chain reaction; ALP, alkaline phosphatase; OSX, osterix; OCN, osteocalcin.

(Sangon Biotech Co., Ltd., Shanghai, China) and annealing temperatures used in this study are listed in Table I. Quantitative PCR (qPCR) was performed with a RealSYBR Mixture (Beijing CoWin Biotech) according to the manufacturer's instructions. The qPCR reactions were performed in the ABI PRISM 7300 sequence detection system (Applied Biosystems, Grand Island, NY, USA). In each reaction, $1 \mu \mathrm{l}$ cDNA, $10 \mu \mathrm{l} 2 \mathrm{X}$ RealSYBR Mixture, and $0.25 \mu \mathrm{M}$ forward and reverse primer in a total volume of $20 \mu \mathrm{l}$ were used. The reaction conditions used were: 1 cycle of $95^{\circ} \mathrm{C}$ for $5 \mathrm{~min}$ followed by 40 cycles of $95^{\circ} \mathrm{C}$ for $15 \mathrm{sec}$, annealing temperature for $30 \mathrm{sec}$ and extension at $72^{\circ} \mathrm{C}$ for $30 \mathrm{sec}$. qPCR for each sample was run in triplicate. $\beta$-actin was used as an internal control, and the results were analyzed using the standard $2^{-\Delta \Delta \mathrm{Ct}}$ method as previously described (20).

Western blot analysis. At the end of treatment, cell culture medium was aspirated and the cells were detached in PBS by scraping. Detached cells were centrifuged at $15,000 \mathrm{x}$ g at $4^{\circ} \mathrm{C}$ for $15 \mathrm{~min}$. Cell pellets were then lysed in $300 \mu \mathrm{l}$ lysis buffer (Cytobuster protein extraction reagent; Novagen) with $25 \mathrm{mM}$ $\mathrm{NaF}, 1 \mathrm{mM} \mathrm{Na}_{3} \mathrm{VO}_{4}$, and $1 \mathrm{X}$ protease inhibitor cocktail. Protein concentrations were quantified by spectrophotometry. For western blotting, an equal amount of protein from each sample was loaded on SDS-PAGE and electrotransferred onto PVDF membranes (Millipore, Bedford, MA, USA). The membranes were then blocked with $5 \%(\mathrm{w} / \mathrm{v})$ bovine serum albumin in
TBST [10 mM Tris, $150 \mathrm{mM} \mathrm{NaCl}$, and 0.1\% (v/v) Tween-20, $\mathrm{pH}$ 7.5] for $1 \mathrm{~h}$ at room temperature, and incubated with primary antibodies incubated with primary antibodies: rabbit polyclonal anti-JNK, phosphorylated JNK, $\beta$-actin, goat polyclonal anti-OSX at dilutions of 1:500 (Santa Cruz Biotechnology, Inc.); rabbit polyclonal anti-ERK1/2 and phosphorylated ERK1/2 at dilutions of 1:1,000 (Cell Signaling Technology, Inc.). The secondary antibodies used for detection were horseradish peroxidase (HRP)-conjugated goat anti-rabbit immunoglobulin $\mathrm{G}(\mathrm{IgG})$ and HRP-conjugated rabbit anti-goat IgG (both from Santa Cruz Biotechnology, Inc.). Chemiluminescence ECL (Beyotime Institute of Biotechnology) was used to detect immunoreactive protein signals. Protein signals were then visualized on film and scanned and quantified using the ImageJ software (National Institutes of Health Image, Bethesda, MA, USA). For re-probing, PVDF membranes were stripped with $0.2 \mathrm{M} \mathrm{NaOH}$ for $10 \mathrm{~min}$ before blocking with another primary antibody. The expression of molecules of interest was determined relative to $\beta$-actin.

Statistical analysis. Data are presented as the means \pm standard deviation (SD) for three or more independent experiments. Significant differences were determined using factorial analysis of variance (ANOVA). Statistical analysis was performed using SPSS13.0 software. $\mathrm{P}<0.05$ was regarded significant and shown with an asterisk in the bar diagrams. 


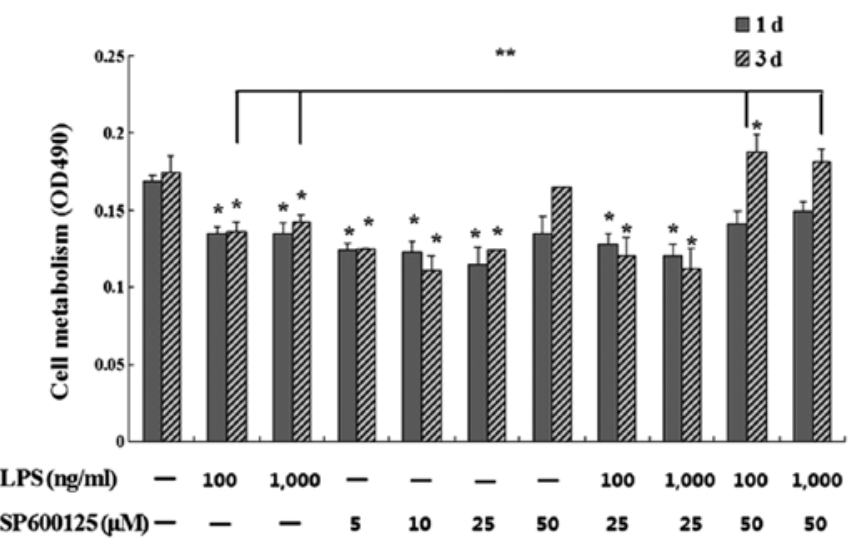

Figure 1. Effect of SP600125 on cell metabolism in MC3T3-E1 cells stimulated with lipopolysaccharide (LPS). Following pretreatment with 5, 10, 15, 25 and $50 \mu \mathrm{M} \mathrm{SP} 600125$ or without SP600125 for $2 \mathrm{~h}$, the cells were treated with 100 and $1,000 \mathrm{ng} / \mathrm{ml}$ LPS or without LPS in the presence of SP600125 for 1 and 3 days. ${ }^{*} \mathrm{P}<0.05$ and ${ }^{* *} \mathrm{P}<0.01$. Data present the mean \pm SD from three independent experiments.
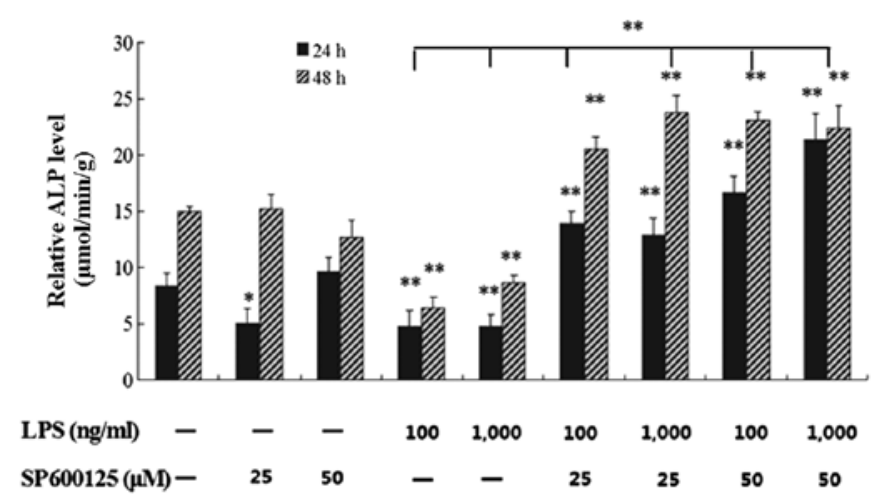

Figure 2. Effect of SP600125 on alkaline phosphatase (ALP) activity in MC3T3-E1 cells stimulated with lipopolysaccharide (LPS). Cells were pretreated with 25 and $50 \mu \mathrm{M}$ SP600125 or without SP600125 for $2 \mathrm{~h}$, and then with 100 and $1,000 \mathrm{ng} / \mathrm{ml}$ LPS or without LPS in the presence of SP600125 for 24 and $48 \mathrm{~h}$. ${ }^{*} \mathrm{P}<0.05$ and ${ }^{* *} \mathrm{P}<0.01$. Data present the mean $\pm \mathrm{SD}$ from three independent experiments.

\section{Results}

Effect of SP600125 on cell metabolism in MC3T3-E1 cells suppressed by LPS. Following pretreatment with 5, 10, 15, 25 and $50 \mu \mathrm{M}$ SP600125 or without SP600125 for $2 \mathrm{~h}$, the cells were treated with 100 and $1,000 \mathrm{ng} / \mathrm{ml}$ LPS or without LPS in the presence of SP600125 for 1 and 3 days. MTT assays showed that SP600125 at $50 \mu \mathrm{M}$ significantly restored cell metabolism downregulated by LPS in MC3T3-E1 cells compared to the remainig treated cultures $(\mathrm{P}<0.01)$ (Fig. 1).

Effect of SP600125 on ALP activity in MC3T3-E1 cells suppressed by LPS. Following pretreatment with 25 and $50 \mu \mathrm{M}$ SP600125 or without SP600125 for $2 \mathrm{~h}$, the cells were treated with 100 and $1,000 \mathrm{ng} / \mathrm{ml}$ LPS or without LPS in the presence of SP600125 for 1 and 2 days. The downregulated ALP activity in MC3T3-E1 cells induced by LPS was significantly restored by SP600125 compared to the non-treated culture at 1 and 2 days $(\mathrm{P}<0.01)$ (Fig. 2).

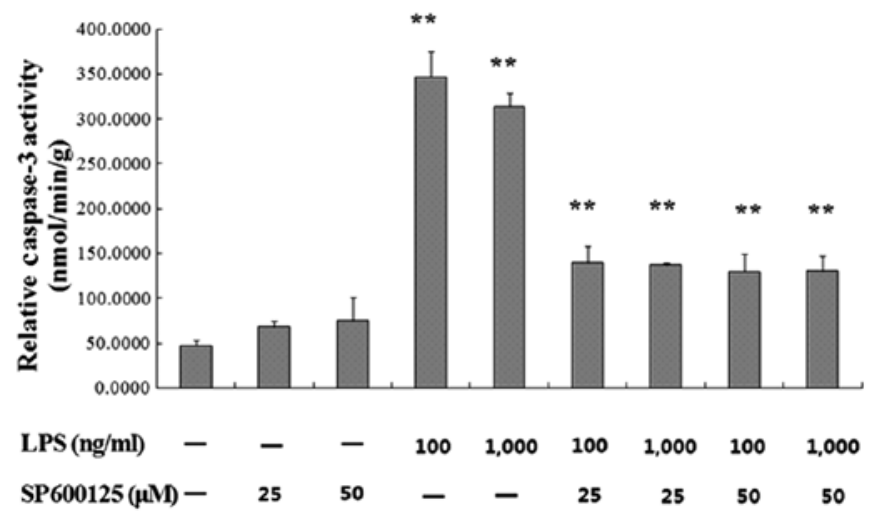

Figure 3. Effect of SP600125 on caspase-3 activity in MC3T3-E1 cells stimulated with lipopolysaccharide (LPS). Following pretreatment with 25 and $50 \mu \mathrm{M}$ SP600125 or without SP600125 for $2 \mathrm{~h}$, the cells were treated with 100 and $1,000 \mathrm{ng} / \mathrm{ml}$ LPS or without LPS in the presence of SP600125 for 1 day. ${ }^{*} \mathrm{P}<0.05$ and ${ }^{* *} \mathrm{P}<0.01$. Data present the mean \pm SD from three independent experiments.

Effect of SP600125 on caspase-3 activity in MC3T3-E1 cells induced by LPS. Cells were pretreated with 25 and $50 \mu \mathrm{M}$ SP600125 or without SP600125 for $2 \mathrm{~h}$, and then with 100 and $1,000 \mathrm{ng} / \mathrm{ml}$ LPS or without LPS in the presence of SP600125 for 1 day. The upregulated caspase-3 activity in MC3T3-E1 cells induced by LPS was significantly downregulated by SP600125 compared to the non-treated culture at 1 day $(\mathrm{P}<0.01)$ (Fig. 3).

Effect of SP600125 on mRNA expression levels of osteoblast-specific genes in MC3T3-E1 cells suppressed by $L P S$. Effect of SP600125 on mRNA expression levels of osteoblast-specific genes such as Runx2, ALP, BSP,OSX, $O C N$ and Collal in MC3T3-E1 cells stimulated with LPS was determined by the qPCR experiment. The results showed that SP600125 has restored the downregulated expression of early-stage osteoblast marker genes such as Runx2, ALP and $B S P$ in MC3T3-E1 cells induced by LPS compared to the non-treated culture at 1 day. However, the expression of latestage genes such as $O S X, O C N$ and Coll $\alpha 1$ was not affected (Fig. 4A and C). This result suggested that SP600125 may play a protective role in early-stage osteoblast differentiation in MC3T3-E1 cells induced by LPS.

Effect of SP600125 on protein levels of osteoblast-specific markers in MC3T3-E1 cells suppressed by LPS. Following pretreatment with 10,25 and $50 \mu \mathrm{M}$ SP600125 or without SP600125 for $2 \mathrm{~h}$, the cells were treated with 100 and 1,000 ng/ $\mathrm{ml}$ LPS or without LPS in the presence of SP600125 for 1 day. The protein expression of early-stage osteoblast markers such as Runx 2 and ALP in MC3T3-E1 cells inhibited by LPS was significantly enhanced by SP600125 compared to the non-treated culture at 1 day, whereas the protein expression of late-stage marker genes such as $O S X$ and $O C N$ was not affected by SP600125 (Fig. 5).

Effect of SP600125 on mRNA and protein expression levels of Bax, Bcl-2 and caspase-3 in MC3T3-E1 cells induced by LPS. Following pretreatment with 10, 25 and $50 \mu \mathrm{M}$ SP600125 or without SP600125 for $2 \mathrm{~h}$, the cells were treated with 100 and 


\section{A}
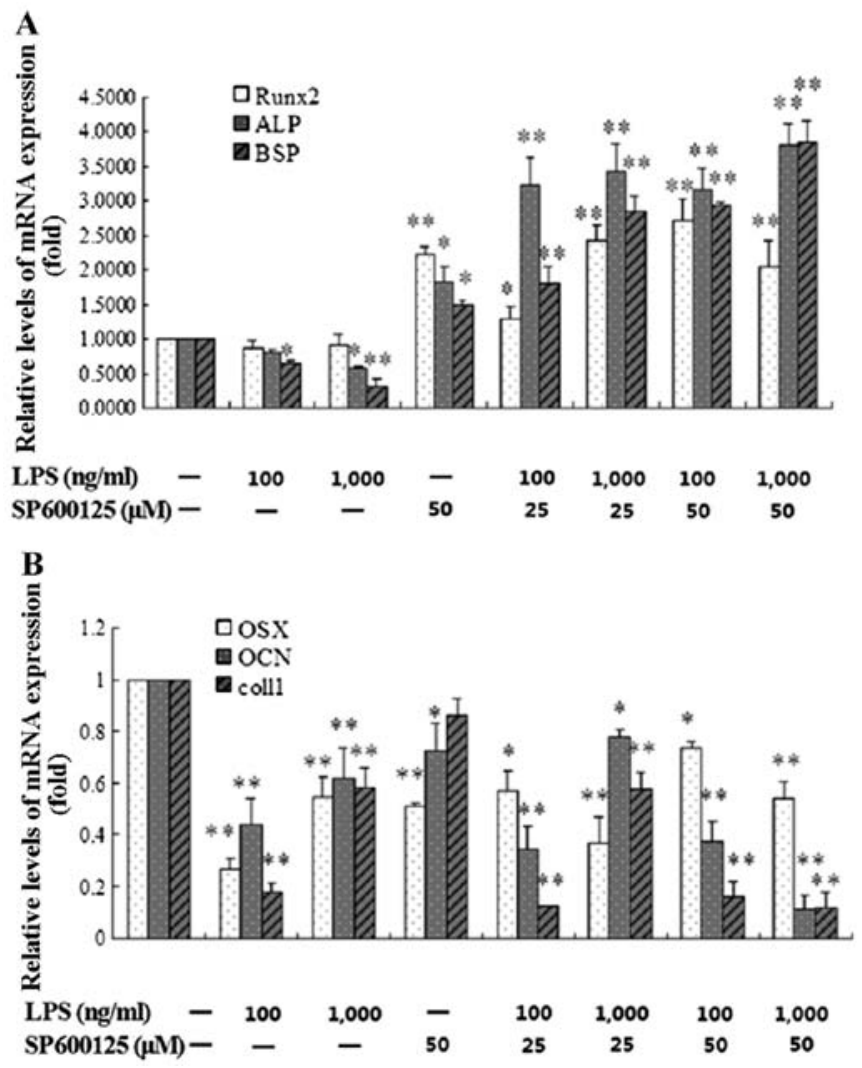

Figure 4. Effect of SP600125 on mRNA expression levels of osteoblastspecific genes in MC3T3-E1 cells stimulated with lipopolysaccharide (LPS) at 1 day. (A) SP600125 restored the downregulated expressions of early-stage osteoblast marker genes such as Runx2, alkaline phosphatase $(A L P)$ and $B S P$. (B) SP600125 did not affect the expression of late-stage genes such as osterix $(O S X)$, osteocalcin $(O C N)$ and Coll $\alpha 1 .{ }^{*} \mathrm{P}<0.05$ and ${ }^{* *} \mathrm{P}<0.01$. Data present the mean \pm SD from three independent experiments.

$1,000 \mathrm{ng} / \mathrm{ml}$ LPS or without LPS in the presence of SP600125 for 1 and 2 day. The upregulated mRNA and protein expression levels of caspase-3 and Bax in MC3T3-E1 cells induced by LPS were significantly decreased by SP600125 compared to the non-treated culture, whereas the downregulated expression of Bcl-2 was significantly enhanced by SP600125 (Figs. 6-8).

Effect of SP600125 on the protein expression of MAPKs in MC3T3-E1 cells induced by LPS. After pretreatment with PD98059 alone, or treatment with PD98059 for $2 \mathrm{~h}$ followed by treatment SP600125 for $2 \mathrm{~h}$, the cells were treated with or without LPS for $30 \mathrm{~min}$ or 1 day in the presence of MAPK inhibitors. The results showed that PD98059 attenuated phosphorylation of ERK1/2 induced by LPS. Additional treatment with SP600125 showed that phosphorylation of ERK1/2 was significantly enhanced. SP600125 significantly enhanced the protein expression of ERK1, but decreased JNK1 expression in MC3T3-E1 cells induced by LPS after SP600125 treatment for $24 \mathrm{~h}$ (Figs. 9 and 10). SP600125 $>10 \mu \mathrm{M}$ was shown to completely decrease the protein expression of JNK1 compared to the nontreated cultures in MC3T3-E1 cells stimulated with LPS.

\section{Discussion}

Excessive bone resorption in chronic inflammatory diseases such as septic arthritis, osteomyelitis, and infected orthopedic
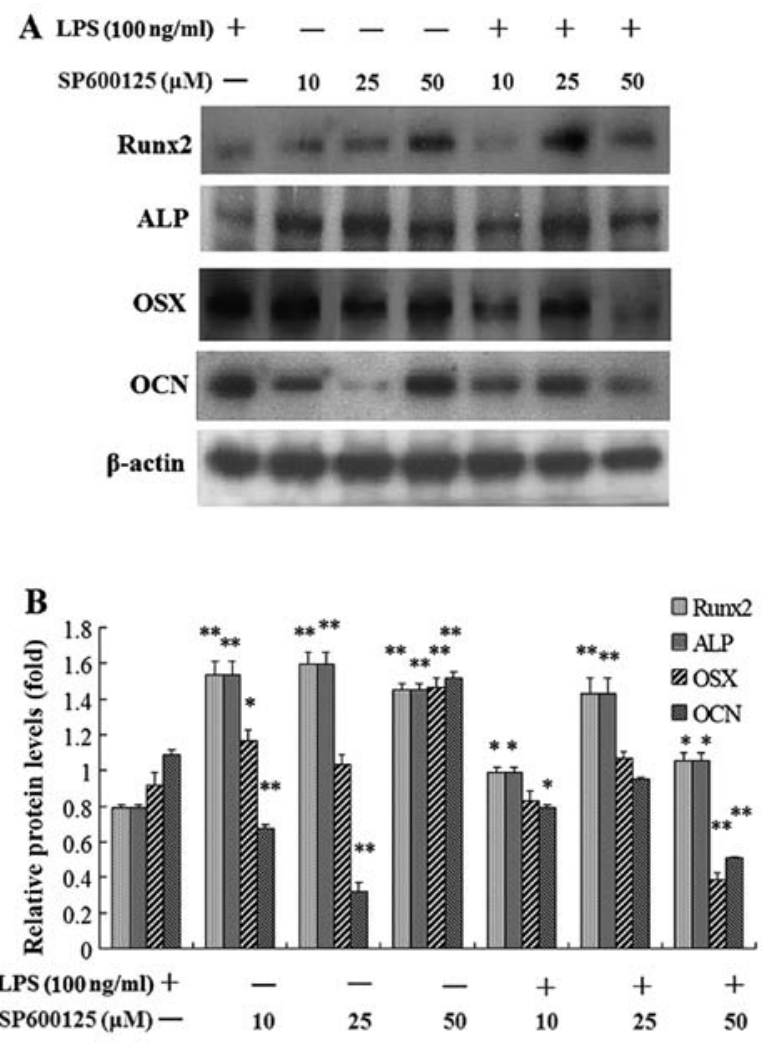

Figure 5. (A and B) Effect of SP600125 on protein levels of osteoblast-specific markers such as Runx2, alkaline phosphatase $(A L P)$, osterix $(O S X)$ and osteocalcin $(O C N)$ in MC3T3-E1 cells stimulated with lipopolysaccharide (LPS) at 1 day. ${ }^{*} \mathrm{P}<0.05$ and ${ }^{* *} \mathrm{P}<0.01$. Data present the mean \pm SD from three independent experiments.

A $\quad \operatorname{LPS}(100 \mathrm{ng} / \mathrm{ml})+-\quad-\quad+\quad++$
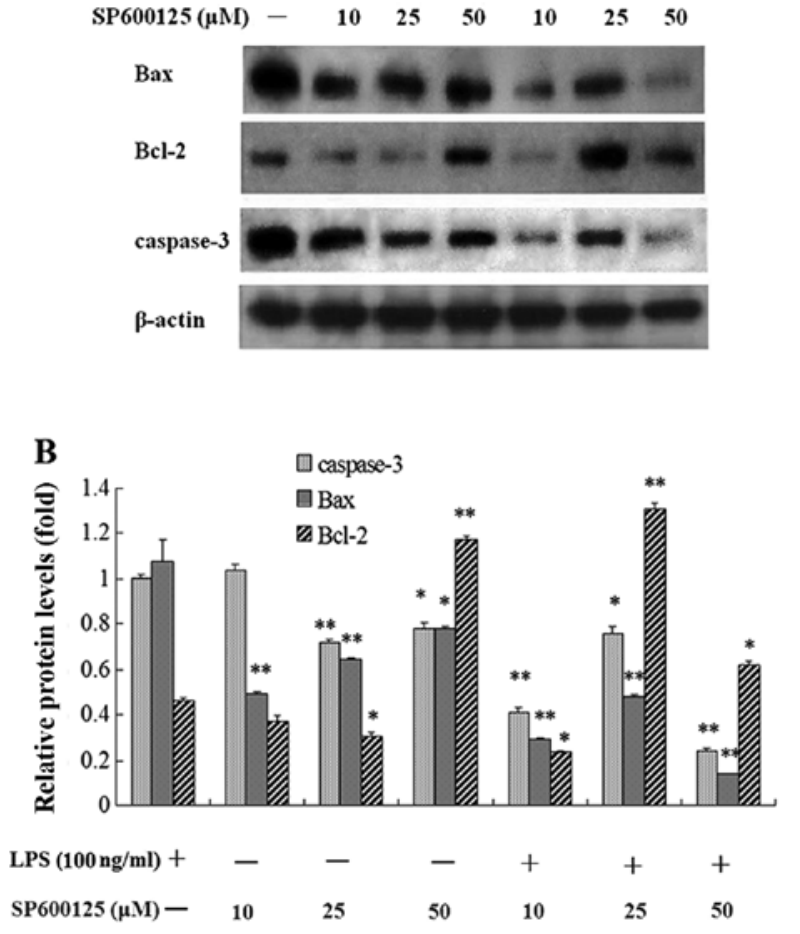

Figure 6. (A and B) Effect of SP600125 on the protein expression of caspase-3, Bax and Bcl-2 in MC3T3-E1 cells stimulated with lipopolysaccharide (LPS) at 24 h. ${ }^{*} \mathrm{P}<0.05$ and ${ }^{* *} \mathrm{P}<0.01$. Data present the mean \pm SD from three independent experiments. 


$\begin{array}{cccccccccc}\text { LPS }(\mathrm{ng} / \mathrm{ml}) & - & 100 & 1000 & 100 & 1000 & 100 & 1000 & 100 & 1000 \\ \text { SP600125 }(25 \mu \mathrm{M}) & - & - & - & + & + & - & - & + & + \\ \text { Time }(\mathrm{h}) & \text { con } & 24 & 24 & 24 & 24 & 48 & 48 & 48 & 48\end{array}$

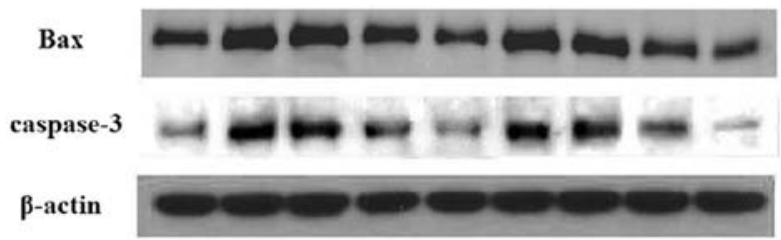

Figure 7. Effect of SP600125 on the protein expression of caspase-3, Bax and Bcl-2 in MC3T3-E1 cells stimulated with lipopolysaccharide (LPS) at $48 \mathrm{~h}$ ${ }^{*} \mathrm{P}<0.05$ and ${ }^{* *} \mathrm{P}<0.01$. Data present the mean $\pm \mathrm{SD}$ from three independent experiments.



Figure 8. Effect of SP600125 on mRNA expression of caspase-3, Bax and Bcl-2 in MC3T3-E1 cells stimulated with lipopolysaccharide (LPS) at $24 \mathrm{~h}$. ${ }^{*} \mathrm{P}<0.05$ and ${ }^{* *} \mathrm{P}<0.01$. Data present the mean $\pm \mathrm{SD}$ from three independent experiments.

implant failure is at least partially caused by bacteria-induced activation of inflammatory responses (2). LPS, a pro-inflammatory glycolipid component of the gram-negative bacteria cell wall, is mediated by gram-negative bacterial bone destruction (3-8). Moreover, LPS inhibits osteoblast differentiation and function in vitro (9-12). Therefore, identification of potential drugs that can restore osteoblast function remains a fundamental objective in the prevention of bone destruction in infective bone diseases. In a previous study we found LPS triggered apoptosis and inhibited osteoblast differentiation through activation of the JNK pathways (19). In this study, we evaluated the effect of JNK inhibition by SP600125 on apoptosis and differentiation in MC3T3-E1 osteoblasts stimulated with LPS. The results show that SP600125 reduced LPS-induced osteoblast apoptosis and restored the early-stage differentiation of osteoblasts inhibited by LPS through MAPK signaling.

Induction of osteoblast apoptosis caused bacteria-induced bone destruction. We evaluated the effect of SP600125 on the apoptosis of MC3T3-E1 cells induced by LPS. The results showed that SP600125 significantly restored the cell metabolism and downregulated the mRNA and protein expression levels of Bax and caspase- 3 as well as caspase-3 activity of MC3T3-E1 cells upregulated by LPS, but increased Bcl-2 expression of MC3T3-E1 cells downregulated by LPS. These



Figure 9. Effect of SP600125 on the protein expression of the phosphorylation of MAPKs in MC3T3-E1 cells stimulated with lipopolysaccharide (LPS) at $30 \mathrm{~min}$. Following pretreament with PD 98059 at $50 \mu \mathrm{M}$ for $2 \mathrm{~h}$, the cells were exposed to SP600125 in the presence of PD98059 for $2 \mathrm{~h}$. Then, $100 \mathrm{ng} / \mathrm{ml}$ of LPS were added, and proteins were prepared $30 \mathrm{~min}$ after LPS treatment. ${ }^{*} \mathrm{P}<0.05$ and ${ }^{* *} \mathrm{P}<0.01$. Data rresent the mean $\pm \mathrm{SD}$ from three independent experiments.
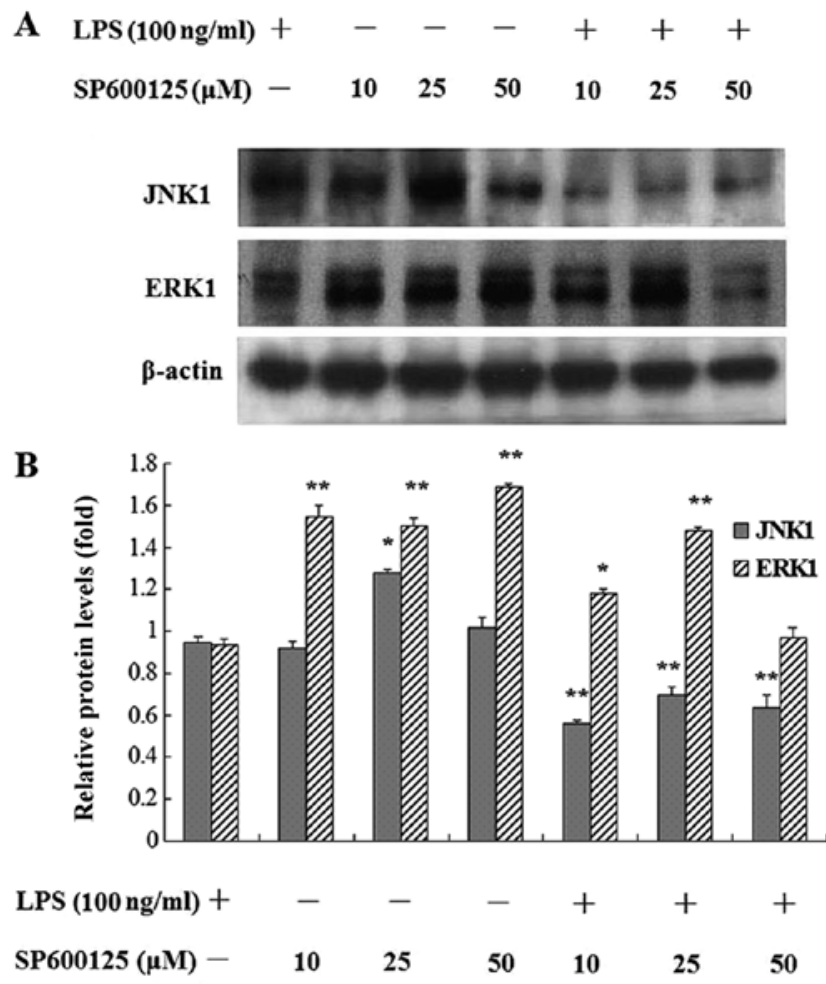

Figure 10. (A and B) Effect of SP600125 on the protein expression of MAPKs in MC3T3-E1 cells stimulated with lipopolysaccharide (LPS) at $24 \mathrm{~h}$. ${ }^{*} \mathrm{P}<0.05$ and ${ }^{* *} \mathrm{P}<0.01$. Data present the mean \pm SD from three independent experiments.

results indicate that SP600125 reduced osteoblast apoptosis of MC3T3-E1 cells induced by LPS. Thus, we suggest that JNK inhibition by SP600125 reduces apoptosis of osteoblasts through the mitochondrial pathway.

Bone formation is a highly regulated process including the differentiation of mesenchymal stem cells to osteoblasts, preosteoblasts and osteoblasts. Runx2, ALP and BSP have been suggested to be involved in the early-stage molecular events 
of osteoblast differentiation. By contrast, OSX, downstream of Runx2, as well as OCN and Coll $\alpha 1$, have been shown to be involved in the late-stage of osteoblast differentiation and bone formation (18,21-26). The reverse effect of SP600125 on LPS-induced inhibition of osteoblast differentiation has been confirmed by evaluating SP600125 on mRNA and protein expression levels of osteoblast-associated genes (18). In this study, SP600125 significantly restored the expression of mRNA and protein of early-stage osteoblast differentiation genes such as Runx2, ALP and BSP in MC3T3-E1 cells suppressed by LPS. However, the expression of late-stage markers such as $O S X, O C N$ and Coll $\alpha 1$ was not affected by SP600125. Our results indicate that the reverse effect of SP600125 on LPS-induced inhibition of osteoblast differentiation may be due to restoration of osteoblast-associated genes.

MAP kinases are activated by various stresses including LPS and influence apoptosis either positively or negatively (27). In many cell types, JNKs contribute to the induction of apoptosis, whereas ERK inhibits apoptotic processes (28-30). In a previous study, treatment with LPS enhanced the protein levels of phosphorylation of ERK1/2 and JNK, while pretreatment with JNK inhibitor SP600125 attenuated the phosphorylation of JNK and ERK1/2 enhanced by LPS. In this study, pretreatment with SP600125 for 1 day decreased the protein level of JNK1 in MC3T3-E1 cells stimulated with LPS, but enhanced protein levels of ERK1. Furthermore, pretreatment with SP600125 and PD98059 decreased the protein level of phosphorylation of JNK but enhanced the protein levels of phosphorylation of ERK1/2 in MC3T3-E1 cells stimulated with LPS. Crossactivation of ERK to JNK has been reported with JNK being the final downstream mediator for cell proliferation and differentiation (31). Our results confirmed that inactivation of JNK activity impaired the ERK-JNK interaction, thereby prolonging the activation of ERK, which was mostly involved in early-stage osteoblast differentiation in LPS-treated MC3T3-E1 cells, but did not affect the late-stage genes which were involved in bone mineralization. The present study also confirms that JNK inhibition may restore the early inhibition of osteoblast differentiation induced by LPS through MAPK signaling (18).

In conclusion, our data suggest that SP600125 may reduce LPS-induced osteoblast apoptosis and restore the early-stage differentiation of osteoblasts inhibited by LPS through MAPK signaling. These findings suggest therapeutic agents that inhibit JNK1 may be used to restore osteoblast function in bacteria-induced bone diseases.

\section{Acknowledgements}

This study was supported by a research grant from the National Natural Science Foundation of China (grant no. 81371981), the School Fund of Luohe Medical College (no. 2012-DF001) and the Fund of Bureau of Science and Technology of Luohe City (no. 2013-001).

\section{References}

1. Roodman GD: Advances in bone biology: the osteoclast. Endocr Rev 17: 308-332, 1996.

2. Nair SP, Meghji S, Wilson M, Reddi K, White P and Henderson B: Bacterially induced bone destruction: mechanisms and misconceptions. Infect Immun 64: 2371-2380, 1996.
3. Orcel P, Feuga M, Bielakoff J and De Vernejoul MC: Local bone injections of LPS and M-CSF increase bone resorption by different pathways in vivo in rats. Am J Physiol 264: E391-E397, 1993.

4. Chiang CY, Kyritsis G, Graves DT and Amar S: Interleukin-1 and tumor necrosis factor activities partially account for calvarial bone resorption induced by local injection of lipopolysaccharide. Infect Immun 67: 4231-4236, 1999.

5. Itoh K, Udagawa N, Kobayashi K, et al: Lipopolysaccharide promotes the survival of osteoclasts via Toll-like receptor 4, but cytokine production of osteoclasts in response to lipopolysaccharide is different from that of macrophages. J Immunol 170: 3688-3695, 2003.

6. Islam S, Hassan F and Tumurkhuu G, et al: Bacterial lipopolysaccharide induces osteoclast formation in RAW 264.7 macrophage cells. Biochem Biophys Res Commun 360: 346-351, 2007.

7. Mörmann M, Thederan M, Nackchbandi I, Giese T, Wagner C and Hänsch GM: Lipopolysaccharides (LPS) induce the differentiation of human monocytes to osteoclasts in a tumour necrosis factor (TNF) alpha-dependent manner: a link between infection and pathological bone resorption. Mol Immunol 45: 3330-3337, 2008.

8. Zou W and Bar-Shavit Z: Dual modulation of osteoclast differentiation by lipopolysaccharide. J Bone Miner Res 17: 1211-1218, 2002.

9. Kadono H, Kido J, Kataoka M, Yamauchi N and Nagata T: Inhibition of osteoblastic cell differentiation by lipopolysaccharide extract from Porphyromonas gingivalis. Infect Immun 67: 2841-2846, 1999.

10. Xing Q, Ye Q, Fan M, Zhou Y, Xu Q and Sandham A: Porphyromonas gingivalis lipopolysaccharide inhibits the osteoblastic differentiation of prosteoblasts by activating Notch1 signaling. J Cell Physiol 225: 106-114, 2010.

11. Bandow K, Maeda A, Kakimoto K, Kusuyama J, Shamoto M, Ohnishi T and Matsuguchi T: Molecular mechanisms of the inhibitory effect of lipopolysaccharide (LPS) on osteoblast differentiation. Biochem Biophys Res Commun 402: 755-761, 2010.

12. Ochi H, Hara Y, Tagawa M, Shinomiya K and Asou Y: The roles of TNFR1 in lipopolysaccharide-induced bone loss: dual effects of TNFR1 on bone metabolism via osteoclastogenesis and osteoblast survival. J Orthop Res 28: 657-663, 2010.

13. Kyriakis JM and Avruch J: Mammalian mitogen-activated protein kinase signal transduction pathways activated by stress and inflammation. Physiol Rev 81: 807-869, 2001.

14. Davis, RJ: Signal transduction by the JNK group of MAP kinases. Cell 103: 239-252, 2000.

15. Chang L and Karin M: Mammalian MAP kinase signalling cascades. Nature 410: 37-40, 2001.

16. Sabapathy K, Hochedlinger K, Nam SY, Bauer A, Karin M and Wagner EF: Distinct roles for JNK1 and JNK2 in regulating JNK activity and c-Jun-dependent cell proliferation. Mol Cell 15: 713-725, 2004.

17. Liu J, Minemoto $Y$ and Lin A: c-Jun N-terminal protein kinase 1 (JNK1), but not JNK2, is essential for tumor necrosis factor alpha-induced c-Jun kinase activation and apoptosis. Mol Cell Biol 24: 10844-10856, 2004.

18. Matsuguchi T, Chiba N, Bandow K, Kakimoto K, Masuda A and Ohnishi T: JNK activity is essential for Atf4 expression and latestage osteoblast differentiation. J Bone Miner Res 24: 398-410, 2009.

19. Guo C, Yuan L, Wang JG, et al: Lipopolysaccharide (LPS) induces the apoptosis and inhibits osteoblast differentiation through JNK pathway in MC3T3-E1 cells. Inflammation 37: 621-631, 2014.

20. Livak KJ and Schmittgen TD: Analysis of relative gene expression data using real-time quantitative PCR and the 2(-Delta Delta C(T)) Method. Methods 25: 402-408, 2001.

21. Kern B, Shen J, Starbuck M and Karsenty G: Cbfa1 contributes to the osteoblast-specific expression of type I collagen genes. J Biol Chem 276: 7101-7107, 2001.

22. Komori T, Yagi H, Nomura S, Yamaguchi A, Sasaki K, Deguchi K, et al: Targeted disruption of Cbfal results in a complete lack of bone formation owing to maturational arrest of osteoblasts. Cell 89: 755-764, 1997.

23. Kim HK, Cho SG, Kim JH, Doan TK, Hu QS, Ulhaq R, et al: Mevinolin enhances osteogenic genes (ALP, type I collagen and osteocalcin), CD44, CD47 and CD51 expression during osteogenic differentiation. Life Sci 84: 290-295, 2009.

24. Thunyakitpisal P, Alvarez M, Tokunaga K, et al: Cloning and functional analysis of a family of nuclear matrix transcription factors (NP/NMP4) that regulate type I collagen expression in osteoblasts. J Bone Miner Res 16: 10-23, 2001. 
25. Nakashima K, Zhou X, Kunkel G, Zhang Z, Deng JM, Behringer RR and de Crombrugghe $B$ : The novel zinc fingercontaining transcription factor osterix is required for osteoblast differentiation and bone formation. Cell 108: 17-29, 2002.

26. Kurata H, Guillot PV, Chan J and Fisk NM: Osterix induces osteogenic gene expression but not differentiation in primary human fetal mesenchymal stem cells. Tissue Eng 13: 1513-1523, 2007.

27. Pearson G, Robinson F, Beers Gibson T, et al: Mitogen-activated protein (MAP) kinase pathways: regulation and physiological functions. Endocr Rev 22: 153-183, 2001.

28. Xia Z, Dickens M, Raingeaud J, Davis RJ and Greenberg ME: Opposing effects of ERK and JNK-p38 MAP kinases on apoptosis. Science 270: 1326-1331, 1995.
29. Park GB, Kim YS, Lee HK, Song H, Cho DH, Lee WJ and Hur DY: Endoplasmic reticulum stress-mediated apoptosis of EBV-transformed B cells by cross-linking of CD70 is dependent upon generation of reactive oxygen species and activation of p38 MAPK and JNK pathway. J Immunol 185: 7274-7284, 2010.

30. Fister S, Günthert AR, Aicher B, Paulini KW, Emons G and Gründker C: GnRH-II antagonists induce apoptosis in human endometrial, ovarian, and breast cancer cells via activation of stress-induced MAPKs p38 and JNK and proapoptotic protein Bax. Cancer Res 69: 6473-6481, 2009.

31. Pedram A, Razandi M and Levin ER: Extracellular signal regulated protein kinase/Jun kinase cross-talk underlies vascular endothelial cell growth factor-induced endothelial cell proliferation. J Biol Chem 273: 26722-26728, 1998. 